\title{
Infecção pelo Vírus da Zika Pode Causar Perda Auditiva Transitória em Adultos
}

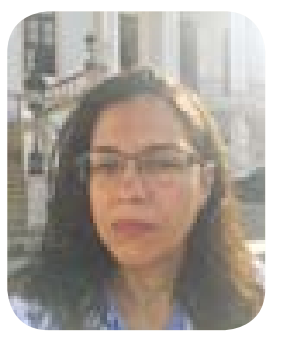

\author{
Viviane S. Boaventura' ${ }^{1}$, Eriko S. Vinhaes ${ }^{1}$, Lislane Dias ${ }^{1}$, Nilvano A. \\ Andrade', Victor H. Bezerra', Anderson T. de Carvalho'. \\ Transient Hearing Loss in Adults Associated With Zika Virus Infection
} Eriko S. Vinhaes, Luciane A. Santos, Lislane Dias, Nilvano A. Andrade, Victor H. Bezerra, Anderson T. de Carvalho, Laise de Moraes, Daniele F. Henriques, Sasha R. Azar, Nikos Vasilakis, Albert I. Ko, Bruno B. Andrade, Isadora C. Siqueira, Ricardo Khouri and Viviane S. Boaventura. Clinical Infectious Diseases ${ }^{\circledR} 2017$; 64(5): 675-7

Palavras-chave: zika, perda auditiva, adulto Keywords: zika, hearing loss, adults

\section{RESUMO}

A infecção congenital pelo vírus da Zika (ZIKAV) é reconhecida como causa de microcefalia, alterações oculares e auditivas ${ }^{1}$. Entretanto, em adultos costuma causar sintomas leves a moderados, como exantema, prurido, febre e artralgia. Complicações neurológicas, como a síndrome de Guillain-Barré, têm sido relacionadas à infecção por ZIKA vírus em adultos e houve um relato de alteração auditiva em paciente da Malásia, sem confirmação audiométrica ${ }^{2,4}$. Nesse artigo, publicado na edição de março de 2017 do respeitado periódico Clinical Infectious Disease (fator de impacto 8.8), descrevemos três casos de infecção aguda por ZIKA V admitidos na emergência do Hospital Santa Izabel, com perda auditiva sensorioneural transitória, documentada por audiometrias seriadas (antes, durante e após a infecção). Além da avaliação clínica e exame audiométrico seriado, foi realizada sorologia para 15 tipos de arbovírus (IgM) e PCR para ZIKA V, dengue e Chikungunya vírus (Tabela 1). Associado aos sintomas sistêmicos, os indivíduos apresentaram zumbido, tontura e perda auditiva na fase aguda da doença (Figura 1). Os sintomas otológicos persistiram por até 28 dias, causando deficiência auditiva moderada a severa e interferindo com a compreensão da fala. Todos as sorologias foram positivas para ZIKA V e negativas para alfavírus e ortobunyavirus. Dois casos apresentaram IgM positiva para DENV, atribuídas à reação cruzada entre flavivírus, conforme sugerido por teste de neutralização (PRNT).

Esse estudo foi pioneiro na confirmação da associação entre a infecção por ZIKA V e a perda auditiva neurossensorial transitória em adultos, que deve ser considerada como uma manifestação durante a infecção aguda por ZIKA V.
Tabela 1 - Resultados de testes laboratoriais para cada um dos pacientes: qPCR, ELISA, Hemaglutinação e títulos de PRNT.

\begin{tabular}{|c|c|c|c|}
\hline Laboratory test & Patient 1 & Patient 2 & Patient 3 \\
\hline \multicolumn{4}{|c|}{ ELISA (IgM): } \\
\hline ZIKAV & POS & POS & POS \\
\hline DENV & NEG & POS & POS \\
\hline CHIKV & NEG & NEG & NEG \\
\hline WNV & NEG & NEG & NEG \\
\hline ILHV & NEG & NEG & NEG \\
\hline SLEV & NEG & NEG & NEG \\
\hline ROCV & NEG & NEG & NEG \\
\hline \multicolumn{4}{|c|}{ Hemagglutination (titers): } \\
\hline ZIKAV & $\geq 1: 1280$ & $\geq 1: 1280$ & $\geq 1: 1280$ \\
\hline WNV & $1: 80$ & $\geq 1: 1280$ & $\geq 1: 1280$ \\
\hline YFV & $1: 160$ & $\geq 1: 640$ & $\geq 1: 640$ \\
\hline YFV-17D & $1: 20$ & $\geq 1: 1280$ & $1: 320$ \\
\hline ILHV & $1: 80$ & $\geq 1: 1280$ & $\geq 1: 640$ \\
\hline SLEV & $1: 20$ & $\geq 1: 1280$ & $\geq 1: 640$ \\
\hline ROCV & $1: 20$ & $\geq 1: 1280$ & $1: 160$ \\
\hline DENV-1 & $1: 160$ & $\geq 1: 640$ & $\geq 1: 320$ \\
\hline DENV-2 & $1: 40$ & $\geq 1: 1280$ & $1: 160$ \\
\hline DENV-3 & $1: 40$ & $\geq 1: 1280$ & $1: 320$ \\
\hline DENV-4 & $1: 40$ & $\geq 1: 1280$ & $\geq 1: 1280$ \\
\hline CHIKV & NEG & NEG & NEG \\
\hline EEEV & NEG & NEG & NEG \\
\hline WEEV & NEG & NEG & NEG \\
\hline MAYV & NEG & NEG & NEG \\
\hline VEEV & NEG & NEG & NEG \\
\hline TCMV & NEG & NEG & NEG \\
\hline
\end{tabular}




\begin{tabular}{cccc}
\hline \hline OROV & NEG & NEG & NEG \\
\hline \hline CATUV & NEG & NEG & NEG \\
\hline \hline
\end{tabular}

ELISA-enzyme-linked immunosorbent assay (Instituto Evandro Chagas);

Hemagglutination assay (Instituto Evandro Chagas); Flavivirus: Zika virus (ZIKAV), West Nilo virus (WNV), Yellow fever virus (YFV), Yellow fever 17D (YFV-17D), llheus virus (ILHV), St. Louis encephalitis virus (SLEV), Rocio virus (ROCV), Dengue virus type 1 (DENV-1), Dengue virus type 2 (DENV-2), Dengue virus type 3 (DENV-3) and Dengue virus type 4 (DENV-4). Alphavirus: Eastern equine encephalitis virus (EEEV), Western equine encephalitis (WEEV), Mayaro virus (MAYV), Mucambo virus (VEEV) and Chikungunya virus (CHIKV). Orthobunyavirus: Tacaiuma virus (TCMV), Oropouche virus (OROV), and Catu virus (CATUV).

\section{REFERÊNCIAS}

1. Petersen LR, Jamieson DJ, Powers AM and Honein MA. Zika Virus. N Engl J Med2016.

2. Paploski IAD, Prates APPB, Cardoso CW, Kikuti M, Silva MMO, Waller LA, et al. Time lags between exanthematous illness attributed to Zika virus, Guillain-Barré syndrome, and microcephaly, Salvador, Brazil. Emerg Infect Dis. 2016.

3. Tappe D, Nachtigall S, Kapaun A, Schnitzler P, Günther S, Schmidt-Chanasi J. Acute Zika Virus Infection after Travel to Malaysian Borneo, September 2014. Emerg Infect Dis. 2015; 21(5): 911-913.

\footnotetext{
1- Serviço de Otorrinolaringologia do HSI

Endereço para correspondência:

vsboaventura@gmail.com
} 